\title{
Flow bench testing of prototype intake manifolds for ultralight aircraft engine
}

\author{
Piotr Swiatek ${ }^{1}$, Pawel Fuc ${ }^{1, *}$, Artur Cebula ${ }^{2}$, and Sebastian Kowalczyk ${ }^{3}$ \\ ${ }^{1}$ Poznan University of Technology, Faculty of Machines and Transport, ul. Piotrowo 3,60-965 Poznan, Poland \\ ${ }^{2}$ Cracow University of Technology, Institute of Thermal Power Engineering, al Jana Pawla II 37, 31-864 Krakow, Poland \\ ${ }^{3}$ Ensys SC, ul. Sliwiny 37, 83-110 Tczew, Poland
}

\begin{abstract}
The article describes the research on the intake manifold for ultralight aircraft engine Vaxell $100 \mathrm{i}$. It presents the actual and new redesigned manifold construction and points out the design requirements. The results of previously made numerical simulation of air flow inside the manifold are discussed. Computer analysis confirmed the appropriateness of internal guide vanes usage to improve the uniform air distribution between cylinders. For verification, a flow bench test stand was made for multicylinder intake manifold testing. A prototype manifold was built with the possibility of guide vane adjustment. The best variant had almost 5 times better uniformity of air distribution comparing to variant without the guide vane. Flow bench results confirmed the conclusions from numerical simulations.
\end{abstract}

\section{Introduction}

The intake system aim is to transport a proper amount of air or air-fuel mixture to the combustion chamber to ensure engine achieves the assumed parameters - power and torque curve, fuel consumption and emission. An intake manifold is located between throttle or carburettor (which is often still used in engines for aircraft propulsion) and head intake ports, and it consists of the main inlet, "plenum" (central air volume) and "runners" (individual tubes leading to cylinder head ports). The construction of intake manifold has to meet specific requirements, of which the most important are $[1,2]$ :

- low air flow resistance,

- even distribution of air flow between each cylinder intake ports [3],

- runner geometry (length, cross-section shape and dimensions) ensuring the usage of pulsating air wave effect that occur in the intake system,

- tailpipe emission $[4,5]$.

In the case of manifolds for ultralight aircraft engines, additional assumptions must be met:

- low weight while retaining sufficient strength and stiffness,

- adequate air flow around the head and cylinders for cooling (manifold construction cannot limit it),

- the low overall height of the intake system (maintaining compact size relative to the external dimensions of the engine and its accessories).

Complying with the above requirements makes the ultralight aircraft intake manifold design process complicated and the final design is a result of technical compromises. For these reasons, we performed a numerical flow simulations, followed by a flow bench testing of prototype manifold.

\section{Research methodology}

\subsection{Research object description}

The object of the research was an intake manifold used in Vaxell 100i engine, which drives many transportation vehicles including ultralight and light aircrafts (Tab. 1, Fig. 1).

Table 1. Vaxell 100i engine specification.

\begin{tabular}{|c|c|}
\hline Number of cylinders & 4 \\
\hline Displacement $\left[\mathrm{cm}^{3}\right]$ & 2276 \\
\hline Cylinder arrangement & boxer \\
\hline Ignition system & dual \\
\hline Fuel supply & multi-point injection \\
\hline Maximum power & $90 \mathrm{hp} / 3100 \mathrm{rpm}$ \\
\hline Maximum torque & $222 \mathrm{Nm} / 2200 \mathrm{rpm}$ \\
\hline
\end{tabular}

The disadvantages of actual intake system design are large numbers of parts and large dimensions. That plays a significant role in the application for ultralight engines, hence a decision of intake system modification. A 3D model (Fig. 2) of changed manifold was designed with one big throttle on the main inlet, smaller plenum and straight runners - in the further part of the article marked as manifold 1. Additionally, variants with guide vanes were designed. This model has been analyzed using Ansys-AIM numerical simulation software [6].

Flow bench testing was performed on newly designed inlet manifold (Fig. 3) with a prototype air tank (Fig. 4) - marked as manifold 2 in the rest of the paper. The special air tank consists of an aluminum cast (1) with a planned upper surface and welded flange. From

* Corresponding author: pawel.fuc@put.poznan.pl

C The Authors, published by EDP Sciences. This is an open access article distributed under the terms of the Creative Commons Attribution License 4.0 (http://creativecommons.org/licenses/by/4.0/). 
the top, the plenum was closed with polycarbonate cover (2) mounted using M5 screws (4). In the cover, a 3D printed guide vane (3) was attached using M5 nuts (5). The position of the cover can be adjusted at a $40^{\circ}$ angle by $12 \mathrm{~mm}$. Additionally, the guide vane can be attached with 3 different angles: $0 \pm 12.5^{\circ}$. The polycarbonate cover is transparent, which makes the possibility of carrying out optical studies of the colored air stream inside the tank. Such research is planned in the future works.

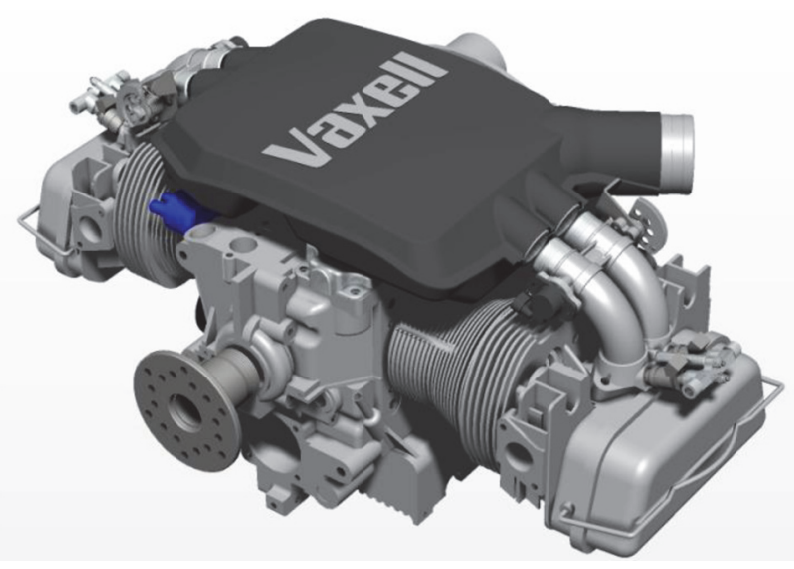

Fig. 1. Vaxell 100i engine with actual intake system.

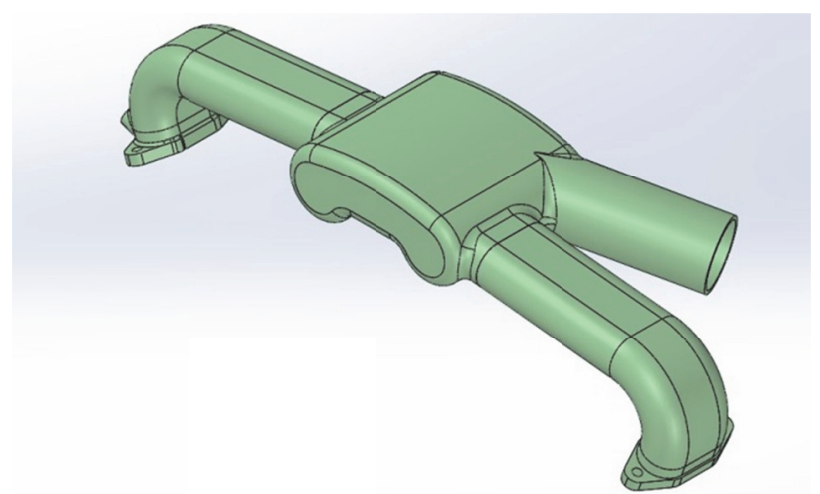

Fig. 2. 3D manifold model for numerical simulations (manifold 1).

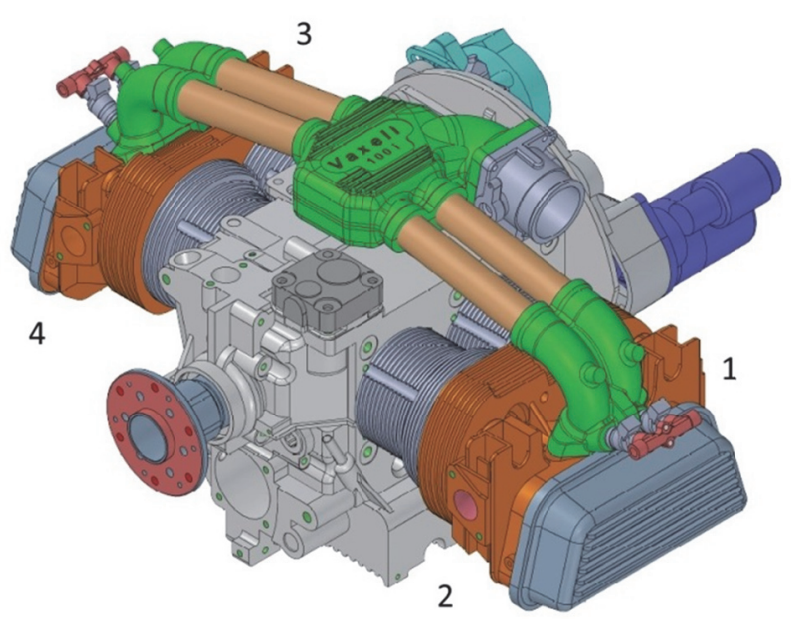

Fig. 2. Vaxell 100i engine with new manifold (manifold 2) with marked numbers of the cylinders.

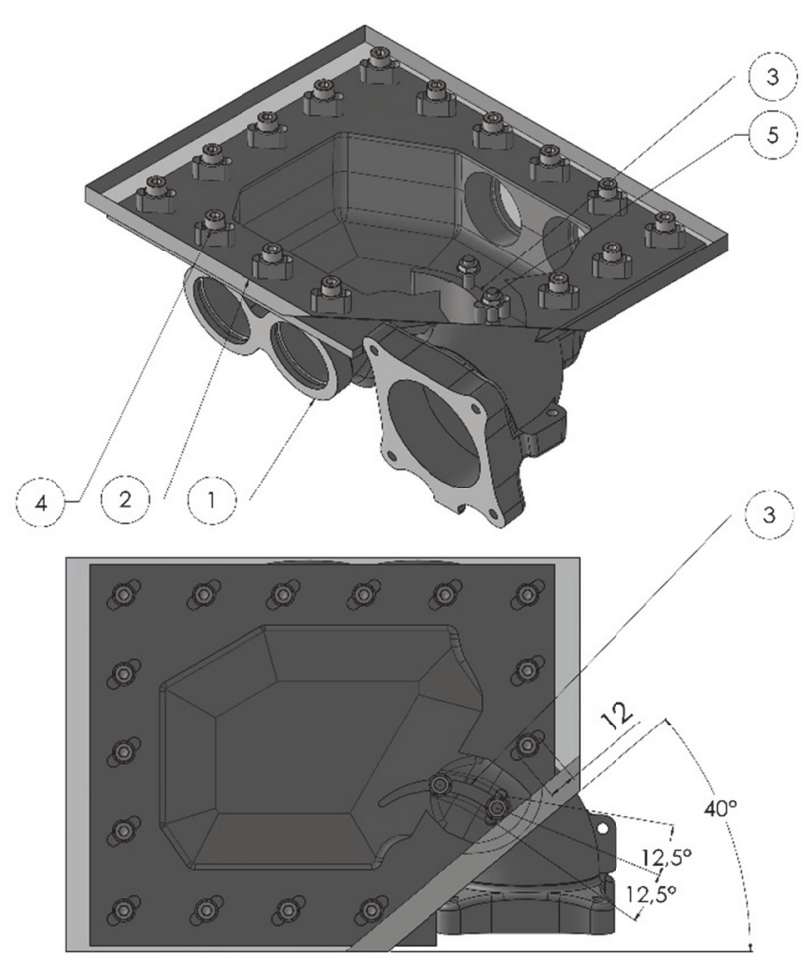

Fig. 4. Prototype air tank for flow bench testing. 1 - bottom part (aluminium cast), 2 - transparent upper cover (polycarbonate), 3 - guide vane ( $3 \mathrm{~d}$ printed plastic), 4 - screws mounting the cover, 5 - nuts mounting the vane.

\subsection{Flow bench tests methodology}

The air flow tests in manifold 2 were performed on a specially built test stand, which is presented in Fig. 5. A fan with regulated speed is mounted in the chamber 1 and provides a partial vacuum. Chamber 2 is used for pressure compensation and measurement, using a piezoresistive sensor, vacuum gauge and U-tube manometer (6). Four channels with flowmeters (2) are located between chamber 2 and tested manifold (5).

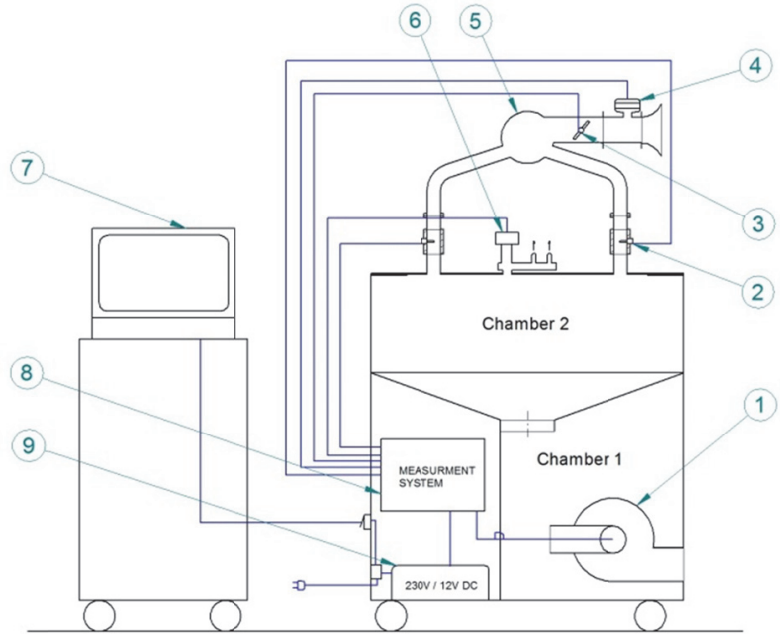

Fig. 5. A schematic of multi-cylinder intake manifold flow bench test stand. 1 - fan, 2 - flowmeters for each cylinder runner, 3 - throttle, 4 - sensors before the throttle, 5 - tested manifold, 6 - pressure sensors, 7 - computer, 8 - measurement system, 9 - power supply. 
At the manifold inlet, a throttle with position sensor and flowmeter is mounted. Before the throttle, there is located an atmospheric pressure and temperature sensor (4). Flowmeter and sensor data is collected by the measurement system (8) with additional power supply (9). Computer (7) records the data from flow bench during tests.

The test bench fan has a $2000 \mathrm{~W}$ motor it is controlled by the inverter. The maximum air flow volume is $1200 \mathrm{~m}^{3} / \mathrm{min}$, which corresponds to flowing air velocity equal $27 \mathrm{~m} / \mathrm{s}$. With these setting, the fan creates a 0,1 bar negative pressure in chamber 1 .

Five identical HFM5 type flowmeters (Fig. 6) were mounted on the test stand. These are a hot film mass airflow sensors which enable to detect the direction of the airflow. Each one has a measurement venturi with a plastic and wire mesh that ensure a uniform distribution of the air stream. Using a standard anemometer, the flowmeter characteristic was determined - dependency of voltage and mass airflow, presented on Fig. 7.

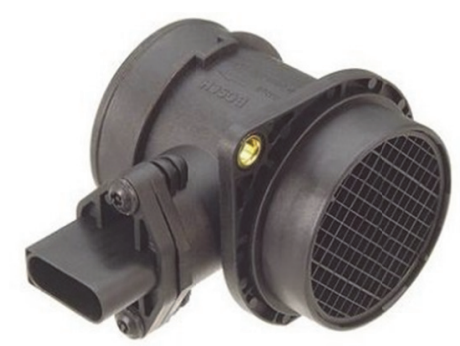

Fig. 6. HFM5 Flowmeter.

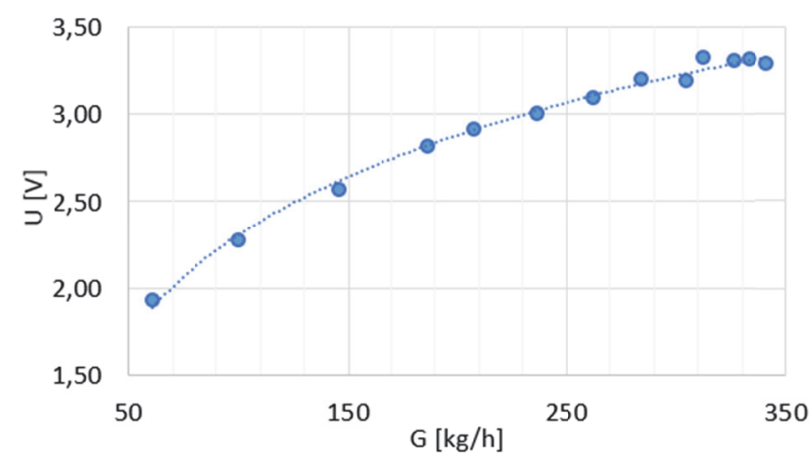

Fig. 7. Flowmeter characteristic.

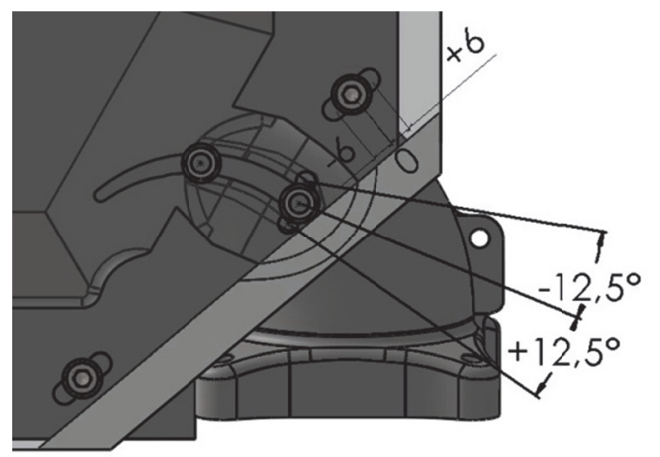

Fig. 8. Range of guide vane position and angle adjustment in prototype manifold.
During prototype manifold testing flow bench fan was set on maximum power and throttle was $100 \%$ open. Tests were performed on manifold 2 with prototype air tank (Fig. 4) which enables to change guide vane position and angle (Fig. 8).

For every test, the mass air flow rate for each cylinder was measured and a factor of uneven distribution of airflow was calculated.

\section{Results}

\subsection{Numerical simulations}

Details of CFD numerical simulations of manifold 1 are described in the paper [4] and were performed using the commercial Ansys-AIM code. The geometry modifications were carried out with the use of SpaceClaim tool. The boundary conditions are assumed as follows. The air mass flow rate of $60 \mathrm{~g} / \mathrm{s}$ is set at the inlet. The flowing fluid is air, which is considered to be an ideal gas. The inlet temperature is set equal to $15^{\circ} \mathrm{C}$. On the outlets the opening boundary condition is set where gauge pressure is equal to -0.1 bar. Since the focus of the work is to optimise the flow path, the thermal effects had not been included in this study. Manifold walls are defined as adiabatic walls which allow setting heat flux across the walls equal to zero $(\dot{q}=$ $=0 \mathrm{~W} / \mathrm{m}^{2}$ ).

Transport equations of the $\mathrm{k}$-e turbulence model were used in the work, because it is considered as the most suitable to predict conditions inside manifold where the flow is swirl dominated.

Unstructured meshes were generated for each geometry. To reconstruct boundary layer and make it possible to calculate flow gradients near wall regions the inflation layers elements were: generated for all manifold and plenum walls. The final mesh size was obtained after the mesh dependency calculations and it has $630 \mathrm{k}$ elements.

Flow analyses were carried out for the baseline case and for proposed solutions representing various guide vanes aimed to provide an even flow split among runners. Fig. 10 shows computational cases that were created by modifying the curvature radius of guide vanes.

The results for manifold without guide vanes showed the uneven distribution of the airflow between cylinders (Fig. 9a). Based on the work [5] the maldistribution coefficient $D_{g}$ was determined according to the formula:

$$
D_{g}=\sqrt{\frac{1}{n-1} \sum_{i=1}^{n}\left(\frac{\dot{m}_{l}}{m_{\text {ave }}}-1\right)^{2}}
$$

where: $n$ - manifold outlet number; $\dot{m}_{\text {ave }}$ - average mass air flow defined by the formula:

$$
\dot{m}_{\text {ave }}=\frac{1}{n} \sum_{n} \dot{m}_{l}
$$

For manifold 1 without guide vane, the $D_{g}$ factor was 0.19 (where 0 - best, 1 - worst) and the outlet 3 had the biggest part of the airflow - $30.1 \%$ (Tab. 2). This 
uneven distribution of airflow causes a smaller volumetric efficiency in cylinder 1 combustion chamber, rough engine work and increase of cylinder temperature. This has a significant impact on the safety of the engine operation. In order to improve the uniformity of airflow distribution between cylinders, use of internal guide vane near the manifold inlet was proposed. Its purpose is to split the airflow and reduction of maldistribution coefficient. Three variants of guide vanes were proposed (Fig. 10) from which variant 3 distributed most evenly air to the outlets (Fig. 9b). For this variant, $D_{g}$ factor was 0.10 (Tab. 2).

Table 2. The results of computer numerical airflow simulations for manifold 1.

\begin{tabular}{|l|c|c|c|c|}
\hline \multirow{2}{*}{} & \multicolumn{2}{|c|}{$\begin{array}{c}\text { Variant without } \\
\text { guide vane }\end{array}$} & \multicolumn{2}{c|}{ Variant 3 } \\
\cline { 2 - 6 } & $\begin{array}{c}\text { Mass } \\
\text { airflow } \\
\mathrm{kg} / \mathrm{s}\end{array}$ & $\begin{array}{c}\text { Flow } \\
\text { split. } \\
\%\end{array}$ & $\begin{array}{c}\text { Mass } \\
\text { airflow } \\
\mathrm{kg} / \mathrm{s}\end{array}$ & $\begin{array}{c}\text { Flow } \\
\text { split. } \\
\%\end{array}$ \\
\hline Outlet 1 & 0.0122 & 20.3 & 0.0138 & 23.0 \\
\hline Outlet 2 & 0.0133 & 22.2 & 0.0146 & 24.4 \\
\hline Outlet 3 & 0.0180 & 30.1 & 0.0143 & 23.8 \\
\hline Outlet 4 & 0.0165 & 27.5 & 0.0174 & 28.9 \\
\hline$D_{g}$ coeficient & \multicolumn{2}{|c|}{0.19} & \multicolumn{2}{c|}{0.10} \\
\hline
\end{tabular}

The simulation results confirmed the principle of using a guide vane in the inlet of the intake manifold in order to improve the uniform distribution of the airflow. Therefore a decision to perform a flow bench testing of prototype manifold was made.

a)

b)

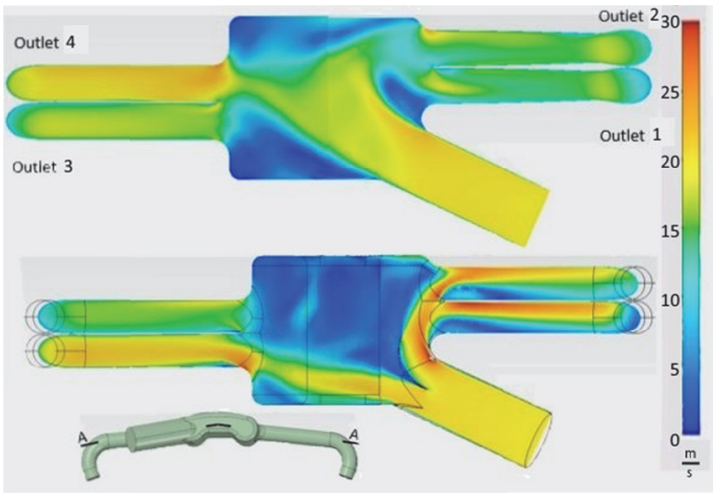

Fig. 9. Comparison of airflow velocity for manifold 1; a) without guide vane, b) with guide vane - variant 3 .

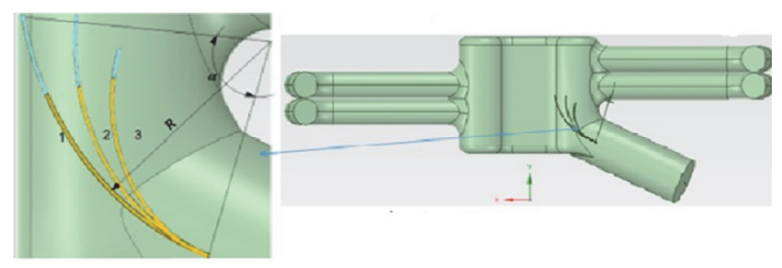

Fig. 10. Three variants of guide vanes in manifold 1 .

\subsection{Flow bench testing}

On the flow bench, air flow measurements were made for the manifold 2 without and with guide vane in 9 different configurations of position and angle (Fig. 8). Without vane, the maldistribution factor $D_{g}=0.44$ was obtained. Results for other configuration are presented in Tab. 3 and the $D_{g}$ vary from 0.09 to 0.60 .

For the configurations: without vane and with guide vane with the best and worst maldistribution factor, additional flow charts of each cylinder are presented in Fig. 11, Fig. 12 and Fig. 13. The numbering of cylinders is presented in accordance with Fig. 3.

Table 3. Results of prototype manifold 2 flow bench testing maldistribution coefficient.

\begin{tabular}{|c|c|c|c|}
\hline $\begin{array}{c}\text { Angle / } \\
\text { Position } \\
\text { of guide vane }\end{array}$ & $-6 \mathrm{~mm}$ & 0 & $+6 \mathrm{~mm}$ \\
\hline$-12.5^{\circ}$ & 0.50 & 0.60 & 0.51 \\
\hline $0^{\circ}$ & 0.20 & 0.24 & 0.25 \\
\hline $12.5^{\circ}$ & 0.09 & 0.17 & 0.12 \\
\hline
\end{tabular}

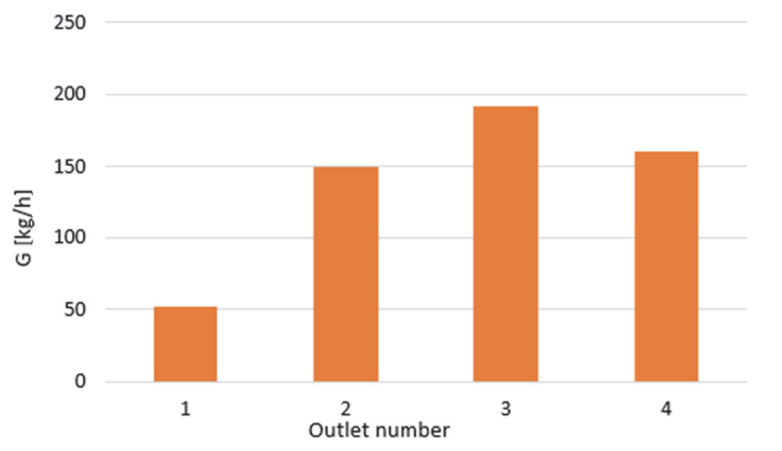

Fig. 11. Mass airflow chart for each cylinder for manifold 2 without guide vane, $D_{g}=0.44$.

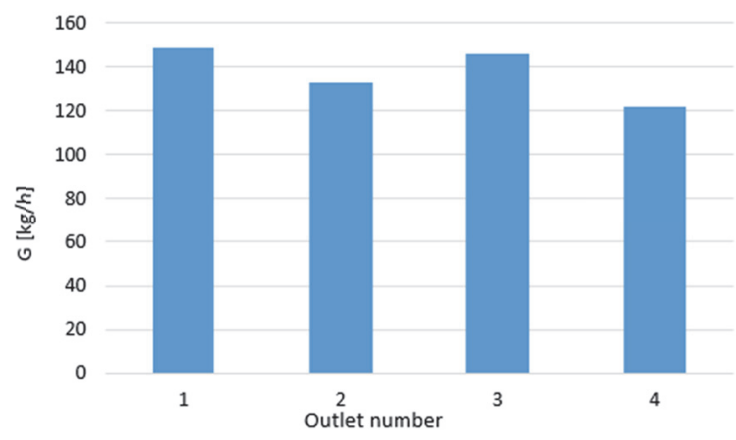

Fig. 12. Mass airflow chart for each cylinder for manifold 2 with guide vane - configuration $-6 \mathrm{~mm},+12.5^{\circ}, D_{g}=0.09$.

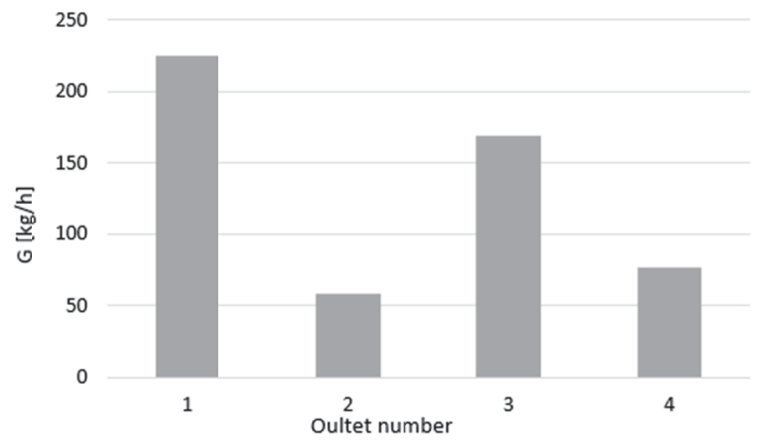

Fig. 13. Mass airflow chart for each cylinder for manifold 2 with guide vane - configuration $01 \mathrm{~mm} ;-12.5^{\circ}, D_{g}=0.60$. 


\section{Conclusions}

Research have shown the correctness of design and construction of a special intake manifold flow test bench. It enables to measure the mass airflow in each of the manifold outlets and analyze its distribution for multicylinder engines.

The flow bench test results confirmed the numerical simulation conclusion, that application of a guide vane inside the intake manifold improves the uniform distribution of the airflow between the cylinders. For the manifold without vane the maldistribution coefficient $D_{g}=0.44$ was obtained while using guide vane in the best configuration $\left(-6 \mathrm{~mm},+12.5^{\circ}\right)$ the factor $D_{g}=0.09$ was obtained. In the worst configuration $\left(0 \mathrm{~mm},-12.5^{\circ}\right)$ $D_{g}$ was 0.60 . In this case, the guide vane distributed the majority of airflow to outlet number 1 and 2, so that other outlet received less air flow.

Performed tests do not take into account the wave pulsation effects which occur in the engine intake system. In order to check its influence in the prototype manifold, engine tests on the dynamometer are planned in the future.

Guide vane is an additional element in the intake manifold and it has an impact on airflow resistance. That is why a study on guide vane influence on air flow parameters is planned.

The authors are pleased to acknowledge the financial support from the National Centre of Research and Development in the framework of Innolot contract POIR/01.02.00-00-0015/1510 for the work presented in this paper.

\section{References}

1. W.W. Pulkrabek, Engineering fundamentals of the internal combustion engine 249 (Pearson Prentice Hall, 2004)

2. H.P. Lenz, Springer Science \& Business Media (2012)

3. L.J. Kapusta, I. Pielecha, K. Wisłocki, A. Teodorczyk, Journal of Thermal Analysis and Calorimetry 123, 819-828 (2016), DOI: 10.1007/s10973-015-4927-z

4. J. Merkisz, J. Markowski, J. Pielecha, WIT Transactions on Ecology and the Environment 174, 219-230 (2013), DOI: 10.2495/AIR130191

5. J. Merkisz, J. Markowski, J. Pielecha, IEEE Vehicle Power and Propulsion Conference VPPC 897-902 (2012)

6. A. Cebula, S. Kowalczyk, P. Swiatek, Proceeding of Modern Power Systems and Units (Krakow, 2016) 